\title{
A CONTEXTUALIZAÇÃO DA QUÍMICA E O MOVIMENTO CTSA
}

\author{
Apresentação: Pôster
}

Patrícia Brito Souza da Nóbrega ${ }^{1}$; Gesivaldo Jesus Alves de Figueirêdo ${ }^{2}$

\section{Introdução}

Pesquisas no âmbito da educação, ensino e aprendizagem têm mostrado que os estudantes desenvolvem melhor a compreensão dos conteúdos quando os educadores deixam de empregar unicamente o conhecimento empírico e passam a utilizar também o conhecimento científico.

A partir disto, verifica-se que utilizar o método da contextualização para compreensão dos conhecimentos para uso no cotidiano, contribui como solução para melhoria do atual contexto escolar. Contudo, mesmo com a recomendação da Lei de Diretrizes e Bases da Educação (LDB - $\mathrm{n}^{\circ}$ 9.394/1997), muitos professores e educadores utilizam com frequência a metodologia tradicional.

Apesar da abordagem dos conteúdos da Química para o Ensino Médio ser distante da realidade vivida por estudantes e professores, a contextualização da Química não deve apenas promover uma ligação artificial entre o conhecimento e o cotidiano, mas propor situações problemáticas reais, onde o aluno, tendo o conhecimento necessário, possa entender, analisar e propor soluções.

Em conformidade com o exposto, o trabalho visou promover o desenvolvimento da educação ambiental contextualizada com conteúdos Químicos, visando à promoção de pensamentos com perspectivas mais críticas e decisórios para compreensão da realidade que os cercam.

\section{Fundamentação Teórica}

\section{A contextualização no ensino de Química e a Educação ambiental}

A contextualização dos conteúdos de Química ministrados em sala de aula denota ensinar para o aluno aspectos importantes do seu cotidiano, de modo a torná-lo capaz de entender, tomar decisões, participar de contextos da Química considerados atuais e interdisciplinares (COSTA, 2010).

\footnotetext{
${ }^{1}$ Licenciatura em Química, IFPB, patriciadanobrega@hotmail.com

2 Professor Doutor, IFPB, gesivaldojesus@hotmail.com
} 
Segundo Fonseca (2011), a mudança nas metodologias tradicionais com a inclusão das aulas experimentais estimula o desenvolvimento conceitual, pois oportuniza os estudantes na elaboração de novas ideias e ao mesmo tempo contribui na ampliação de seus conceitos.

Reforçando que os conceitos de Química abordados em sala de aula de forma teórica e sem aplicação prática e contextualizada podem ser trabalhados de forma diferenciada, ou seja, aplicando métodos práticos como a contextualização que leva o discente a despertar suas curiosidades e instigá-los a correlacionar a teoria com a vivência prática.

Apesar disto, muitos são os educadores que fazem uso desta ferramenta tão importante de forma errônea, como é bem ilustrado por Santos (2007):

[...] há uma compreensão restrita do que vem a ser o ensino do cotidiano na escola. Muitos professores consideram o princípio da contextualização como sinônimo de abordagem de situações do cotidiano, no sentido de descrever, nominalmente, o fenômeno com a linguagem científica. Essa abordagem é desenvolvida, em geral, sem explorar as dimensões sociais nas quais os fenômenos estão inseridos. (SANTOS, 2007).

Todavia, fazer uso de contextualização no ensino de ciências é mais do que simplesmente dar exemplos do cotidiano, é promover o movimento de ciência-tecnologia-sociedade-ambiente (CTSA) integrado aos conteúdos, buscando promover as reflexões mais críticas, aplicabilidade dos assuntos no cotidiano, bem como retomar e impulsionar a educação ambiental em sala de aula.

O desenvolvimento do movimento CTSA nas aulas engloba a elaboração de valores vinculados aos interesses coletivos, auxiliando no desenvolvimento de consciências mais críticas, com tomada de decisões a partir da compreensão dos fatos que os cercam e, posteriormente, atuar na determinação da solução (SANTOS, 2007).

Neste sentido, mais do que ao fim da exposição do conteúdo dar exemplos do cotidiano, pode ser desenvolvida uma aula dialogada com situações do cotidiano a fim de problematizar, explorando ao máximo este recurso, procurando o entendimento da colocação exposta, buscando conceitos científicos para explicar e solucioná-las, estimulando uma reflexão crítica e uma aprendizagem significativa, além de uma ligação mais forte entre o cotidiano e os conteúdos.

\section{Qualidade de água e formas de captação}

A água é o maior recurso natural e corresponde à maior parte da superfície do globo terrestre. É essencial à manutenção da vida, seja ela animal, vegetal ou humana, bem como para as atividades do dia-a-dia, higiene, preparação de alimentos, entre outros usos e aplicações.

Assim, visando qualidade de vida, foi surgindo a necessidade do desenvolvimento de padrões de qualidade para analisar aquela água destinada ao consumo humano e processos de tratamento que a enquadrasse no padrão de potabilidade. 
Para tanto, foram criadas as companhias de abastecimento público de água, as quais, além de captar a água do manancial, realizam a caracterização daquele solvente, verificando quais os valores dos parâmetros, assim como aplicam diversos processos de tratamento até enquadrar o solvente nos padrões aceitos pela legislação vigente, para, posteriormente, enviar para o reservatório elevado, onde de lá irá ser distribuída a comunidade.

Tal informação corrobora para a importância do desenvolvimento da educação ambiental para que os estudantes possam analisar e identificar a água destinada ao consumo, bem como propor soluções para adequação dessas águas.

\section{Metodologia}

O trabalho foi desenvolvido em uma turma do $2^{\circ}$ ano do Curso Técnico de Controle Ambiental Integrado ao Ensino Médio, do Instituto Federal de Educação, Ciência e Tecnologia da Paraíba - IFPB (campus João Pessoa), na qual foram ministradas aulas dialogadas associadas a aulas práticas, contextualizando os conteúdos químicos (interação química, ligações químicas, processos de separação de misturas e superfície de contato), por meio da promoção do movimento de ciência-tecnologia-sociedade-ambiente - CTSA.

O desenvolvimento de uma aula dialogada tornou possível problematizar a aula, avaliando o conhecimento prévio dos educandos com o intuito de explanar com os futuros conhecimentos de forma a se correlacionar com estes e terem maior ligação no cognitivo.

Este processo de aprendizagem permite que o estudante seja ativo, pois tem a ação e reflexão dos conteúdos, prevalecendo a "construção" do conhecimento, e assim, promovendo uma aprendizagem significativa para o sujeito.

Para tanto, foi questionado a importância da água em nossas vidas e o que estabelece a Portaria $n^{\circ}$ 2.914/2011 do Ministério da Saúde, para que assim os estudantes tivessem maior conhecimento sobre os padrões de potabilidade e qualidade de água.

Desta forma, foi possível realizar a conexão com a importância da existência das ETAs, questionando/problematizando: para que servem? Como funcionam? Socializando que a água de consumo direto deve atender a determinados padrões de potabilidade, processo de tratamento e distribuição de água com qualidade a todos.

Contudo, as ETAs não atendem a todos, então foram exemplificadas, pelos estudantes, outras formas de obtenção deste importante recurso hídrico. 
Com a exibição desta imagem, foram feitos questionamentos sobre o que poderia ser feito para tornar esta água potável e se nas condições em que ela se encontra poderia ser consumida pela comunidade.

Partindo deste contexto, houve a perspectiva de conscientização e reflexão crítica pelos discentes sobre a qualidade de água e identificação de processos de tratamento de água a fim de garantia de qualidade de vida.

Posteriormente, houve a promoção desta contextualização com uma forma alternativa para tratamento desta água pela comunidade utilizando para tanto o método de adsorção, explicando como funciona por meio da conexão com os conteúdos químicos (interação química, ligações químicas, processos de separação de misturas e superfície de contato). Permitindo, assim, a aplicação dos conteúdos em uma situação do cotidiano, a fim de torná-los tangíveis, favorecendo uma aprendizagem significativa, além de relacioná-los com a vivência do curso técnico.

Em seguida, houve a execução da técnica de adsorção, que consiste em um método alternativo de tratamento de águas, o qual pode ser empregado como forma de contextualização destes conteúdos, principalmente quando são ministrados para turmas do Curso Técnico de Controle Ambiental Integrado ao Ensino Médio. Pois, compreende-se que para os alunos deste curso será importante ter essa oportunidade de entender como funciona a aplicação deste processo, correlacionando a teoria e a prática.

Por fim, foi solicitado a elaboração de relatórios experimentais para avaliar a abordagem.

\section{Resultados e Discussão}

Com o desenvolvimento da metodologia mencionada, verificou-se que é possível o desenvolvimento da educação ambiental correlacionada e contextualizada com os conteúdos Químicos.

Ilustrando que o desenvolvimento adequado de uma contextualização é mais do que simples citações de exemplos, mas que busca conceitos científicos para explicar e solucioná-las, estimulando uma reflexão crítica e uma aprendizagem significativa, além do fortalecimento da ligação entre o cotidiano e os conteúdos, que, desta forma, promove uma aprendizagem significativa.

Desta forma, trabalhar com a educação ambiental permitiu executar bem e de forma adequada o método da contextualização, bem como a importância do movimento de ciênciatecnologia-sociedade-ambiente (CTSA) integrado aos conteúdos, oportunizando buscar conceitos 
científicos para explicar e solucionar situações do dia-a-dia, estimulando uma reflexão crítica e uma aprendizagem significativa.

Logo, isto pode ser comprovado por meio da análise dos relatórios experimentais dos educandos, nos quais eles explicaram bem a prática desenvolvida, utilizaram de conceitos científicos em suas colocações, além de elogiarem a metodologia e solicitarem o desenvolvimento de mais aulas como estas

\section{Conclusões}

A metodologia proposta permitiu a execução de aulas contextualizadas promovendo o movimento de ciência-tecnologia-sociedade-ambiente (CTSA) integrado aos conteúdos, concluindo que auxilia no desenvolvimento de consciências mais críticas e a capacidade de analisar e interpretar situações-problema que os cercam, podendo atuar na determinação da solução. Assim como é uma aula mais atrativa e motivadora para os estudantes, os quais se colocam mais participativos e atuantes na construção da aprendizagem significativa.

\section{Referências}

AUSUBEL, David P. Aquisição e retenção de conhecimentos: uma perspectiva cognitiva. Lisboa: Plátano Edições Técnicas, $1^{\text {a }}$ edição, 2001.

BRASIL. Lei de Diretrizes e Bases da Educação Nacional, Lei no. 9.394, de 20 de dezembro de 1996.

Parâmetros Curriculares Nacionais para o Ensino Médio. Brasília: MEC/SEMTEC, 1999.

COSTA, L. C.; MARCIANO, E. P.; CARNEIRO, G. M. B.; SOUSA, R. M. DE; NUNES, S. M. A Química Forense como unidade temática para o desenvolvimento de uma abordagem de Ensino CTS em Química Orgânica. XV Encontro Nacional de Ensino de Química (XV ENEQ) - Brasília, DF, Brasil - 21 a 24 de julho de 2010.

FIGUEIRÊDO, G. J. A. Tecnologia Sustentável para Tratamento de Efluentes de Estações de Tratamento de Água com Aproveitamento na Agricultura Irrigada. 2013. Tese de Doutorado. Centro de Tecnologia e Recursos Naturais, UFCG. Campina Grande.

FONSECA, M.R.M. Completamente Química: Química Geral, São Paulo, 2001.

SANTOS, W. L. P. dos; Contextualização no Ensino de Ciências por meio de temas CTS em uma perspectiva crítica. Ciência \& Ensino. Número especial: "Educação em Ciência, Tecnologia, Sociedade e Ambiente", vol. 1, 2007.

Informações sobre a água - Abastecimento de água (com ênfase em desinfecção). Disponível em <http://www.saaeangra.com.br/php/material_agua.php> Acesso em: 4 de abril de 2015. 